\title{
Multi Objective Optimization Model of CNC Turning for Minimizing Processing Time and Carbon Emission with Real Machining Application
}

\author{
Cucuk Nur Rosyidi $^{1}$ (iD), Wahyu Widhiarso ${ }^{2}$ (D) Eko Pujiyanto $^{1}$ (i) \\ 'Industrial Engineering Department, Universitas Sebelas Maret (Indonesia) \\ ${ }^{2}$ Industrial Engineering, Universitas Jenderal Ahmad Yani Yogyakarta (Indonesia) \\ cucuknun@staff.uns.ac.id,wwridhiarso@ymail.com,ekopuizianto@ft.uns.ac.id
}

Received: July 2020

Accepted: February 2021

\section{Abstract:}

Purpose: The purpose of this research is to develop an optimization model of CNC turning process. The objective function of the model is to minimize processing time and carbon emission. We implemented the results of optimization with real machining application using a certain workpiece.

Design/methodology/approach: The model in this research used multi objective optimization involving two objective functions, namely processing time which includes cutting time and auxiliary time and carbon emissions resulted from the electricity energy consumptions, cutting tool, cutting fluid or coolant, raw materials production, and chip removal.

Findings: The results of multi objective optimization indicate that the model can be used to minimize the processing time and carbon emissions with the optimal cutting speed and feed rate are $193.7 \mathrm{~m} / \mathrm{minute}$ and $0.405 \mathrm{~mm} / \mathrm{rev}$. The results of sensitivity analysis showed that the higher weights of processing time will decrease the cutting speed, while the higher carbon emissions weight will result in faster cutting speed. The weight has no effects on feed rate.

Originality/value: This paper gives a real machining application to show the applicability of the optimization model

Keywords: multi objective optimization, prcess parameters, processing time, carbon emission, CNC turning, real machining application

\section{To cite this article:}

Rosyidi, C.N., Widhiarso, W., \& Pujiyanto, E. (2021). Multi objective optimization model of CNC turning for minimizing processing time and carbon emission with real machining application. Journal of Industrial Engineering and Management, 14(2), 376-390. https://doi.org/10.3926/jiem.3269

\section{Introduction}

In tight competition, efficiency is important for manufacturing companies to produce competitive product in the market (Berk, 2010). One way to achieve high efficiency is by the use of modern manufacturing technology such as CNC machines. CNC machining is a process method used in many manufacturing systems ( $\mathrm{Yi}$, Li, Tang \& Chen, 2015). Two important CNC machining processes are milling and turning processes. According to Rochim (2007), 
turning process is a process forming of the workpiece by material removal a linearly (longitudinal, horizontal or angular). CNC turning machine is very effectively used to produce a workpiece in large quantities and in the same time some savings are obtained in the form of cutting tool, processing time, and machining costs (Subagio, 2012).

In machining process, the cutting parameters, namely cutting speed, feed rate, and depth of cut will directly affect the workpiece surface quality, production efficiency, production cost, energy consumption, and carbon emissions (Rajemi, Mativenga \& Aramcharoen, 2010; Yi et al., 2015; Liu, Sun, Lin, Zhao \& Yang, 2016). In cutting process, the metal raw material, such as iron, steel, or aluminum has the highest energy consumption. The machining process such as milling, turning, and other metal cutting consumed the energy of about 66-82 MJ $/ \mathrm{kg}$ which is $50 \%$ higher than the energy consumption of the forging and casting processes (Sun \& Zhang, 2012). Carbons are emitted from the use of energy in those processes. Hence, reducing the carbon emissions in such processes is served as a strategy to create green production (Hassine, Barkallah, Bellacicco, Louati, Riviere \& Haddar, 2015).

Many studies have been conducted in CNC machining optimization model development to minimize several objectives, such as processing time, carbon emissions or combination of both objective functions. Rajemi et al. (2010) developed a total energy consumption model on turning process by optimizing tool life to minimize the energy consumption. Deepak (2012) developed an optimization model to minimize production time on turning process to determine the optimal value of cutting speed and feed rate. Sai, Charyulu and Nayak (2012) developed a multi-objective optimization model in the CNC turning to minimize the production time and production cost to find optimal cutting parameters, namely cutting speed and feed rate. The model was solved using Weighted Sum Genetic Algorithm. Li, Tang, Cui and Yi (2013) developed an analytical model to reduce the carbon emissions from various $\mathrm{CNC}$ machining processes. They considered several sources of carbon emissions such as electricity, cutting tool production, cutting fluid production, raw material production, and chip removal. In that research, the carbon emissions came from CNC machining systems are evaluated using various cutting speed. The research results indicated that faster cutting speed will increase the total carbon emissions. Jabri, Barkany and Khalfi (2013) developed a multi-objective optimization model of the turning multi-pass process to minimize cutting cost and tool life. The research considered cutting speed, feed rate, and depth of cut as the decision variables.

Yi et al. (2015) developed a multi-objective optimization model to minimize production time and carbon emissions in the $\mathrm{CNC}$ machining. They considered cutting speed and feed rate as the decision variables. In that research, the production time consists of the cutting time, tool changing time, and auxiliary time. The auxiliary time are related with the approach and escape time of cutting tool. The carbon emissions are obtained from the electricity consumption, cutting tool, and cutting fluid. The carbon emissions of raw material and removal chip did not include in the model due to their insignificant effects on the cutting parameter. The model was then solved using Non-dominated Sorting Genetic Algorithm (NSGA II) method.

Liu et al. (2016) developed a multi-objective optimization model in the cutting process to minimize processing time and carbon emissions to find the optimal value of cutting speed and feed rate. In that research, the machining costs included in the carbon emissions as the utility function to select and evaluate the optimal solution of the cutting parameters. The carbon emissions are resulted from the electricity energy consumption, cutting tool, and cutting fluid or coolant. The processing time consists of starting time, tool setting time, tool changing time, idle running time, and cutting time. The model was solved using Non-dominated Sorting GA (NSGA II) method.

Hamada, Rosyidi and Jauhari (2017) developed a multi-objective optimization model of the CNC machining to minimize processing time and environmental impact with cutting speed and feed rate as the decision variables. In that research, the processing time comprises of cutting time, tool changing time, and auxiliary time. The environmental impact was obtained by converting the environmental burden into eco-indicator 99 unit using LCA (Life Cycle Assessment) approach as the basis of analysis. Several aspects of the environmental impacts were included in the model, namely energy (electricity and compressed air), water uses, and by-product $\left(\mathrm{CO}_{2}\right.$, landfillable and hazardous waste, recyclable materials). Based on Hamada et al. (2017), Widhiarso and Rosyidi (2018) developed a multi-objective optimization model by modifying the objective function from production time into production cost for $\mathrm{CNC}$ turning process. Those two researches were solved using Oracle Crystal Ball software. The summary of the related literature review is shown in Table 1. 


\begin{tabular}{|c|c|c|c|c|c|c|c|c|c|c|}
\hline Model Components & $\begin{array}{c}\text { Rajemi } \\
\text { et al. } \\
\text { (2010) }\end{array}$ & $\begin{array}{c}\text { Deepak } \\
\text { (2012) }\end{array}$ & $\begin{array}{l}\text { Sai } \\
\text { et al. } \\
\text { (2012) }\end{array}$ & $\begin{array}{l}\text { Jabri } \\
\text { et al. } \\
\text { (2013) }\end{array}$ & \begin{tabular}{c|}
$\mathrm{Li}$ \\
et al. \\
(2013)
\end{tabular} & $\begin{array}{c}\text { Yi } \\
\text { et al. } \\
\text { (2015) }\end{array}$ & $\begin{array}{c}\text { Liu } \\
\text { et al. } \\
\text { (2016) }\end{array}$ & $\begin{array}{c}\text { Hamada } \\
\text { et al. } \\
\text { (2017) }\end{array}$ & $\begin{array}{l}\text { Widhiarso } \\
\text { and Rosyidi } \\
\text { (2018) }\end{array}$ & $\begin{array}{c}\text { This } \\
\text { Research }\end{array}$ \\
\hline \multicolumn{11}{|l|}{ Objective Function } \\
\hline Processing time & & $\sqrt{ }$ & $\sqrt{ }$ & & & $\sqrt{ }$ & $\sqrt{ }$ & $\sqrt{ }$ & & $\sqrt{ }$ \\
\hline Carbon emission & $\sqrt{ }$ & & & & $\sqrt{ }$ & $\sqrt{ }$ & $\sqrt{ }$ & & & $\sqrt{ }$ \\
\hline Environmental impact & & & & & & & & $\sqrt{ }$ & $\sqrt{ }$ & \\
\hline Production cost & $\sqrt{ }$ & & $\sqrt{ }$ & $\sqrt{ }$ & & & & & $\sqrt{ }$ & \\
\hline Minimize tool life & & & & $\sqrt{ }$ & & & & & & \\
\hline \multicolumn{11}{|l|}{ Decision Variable } \\
\hline Cutting speed & $\sqrt{ }$ & $\sqrt{ }$ & $\sqrt{ }$ & $\sqrt{ }$ & $\sqrt{ }$ & $\sqrt{ }$ & $\sqrt{ }$ & $\sqrt{ }$ & $\sqrt{ }$ & $\sqrt{ }$ \\
\hline Feed rate & $\sqrt{ }$ & $\sqrt{ }$ & $\sqrt{ }$ & $\sqrt{ }$ & $\sqrt{ }$ & $\sqrt{ }$ & $\sqrt{ }$ & $\sqrt{ }$ & $\sqrt{ }$ & $\sqrt{ }$ \\
\hline Depth of cut & & & & $\sqrt{ }$ & $\sqrt{ }$ & & & & & \\
\hline \multicolumn{11}{|l|}{ Problem Solving } \\
\hline NSGA II & & & & & & $\sqrt{ }$ & $\sqrt{ }$ & & & \\
\hline Genetic Algorithm & & & $\sqrt{ }$ & $\sqrt{ }$ & & & & & & \\
\hline $\begin{array}{l}\text { Geometric } \\
\text { Programming }\end{array}$ & & $\sqrt{ }$ & & & & & & & & \\
\hline Oracle Crystal Ball & & & & & & & & $\sqrt{ }$ & $\sqrt{ }$ & $\sqrt{ }$ \\
\hline Other Opti. Software & $\sqrt{ }$ & & & & $\sqrt{ }$ & & & & & \\
\hline \multicolumn{11}{|l|}{ Processing Time } \\
\hline Starting time & $\sqrt{ }$ & & $\sqrt{ }$ & & & & $\sqrt{ }$ & & & $\sqrt{ }$ \\
\hline Tool setting time & & $\sqrt{ }$ & & & & & $\sqrt{ }$ & & & $\sqrt{ }$ \\
\hline Tool changing time & $\sqrt{ }$ & $\sqrt{ }$ & $\sqrt{ }$ & & & $\sqrt{ }$ & $\sqrt{ }$ & $\sqrt{ }$ & $\sqrt{ }$ & $\sqrt{ }$ \\
\hline Idle running time & & & & & & & $\sqrt{ }$ & & & $\sqrt{ }$ \\
\hline Cutting time & $\sqrt{ }$ & $\sqrt{ }$ & $\sqrt{ }$ & $\sqrt{ }$ & $\sqrt{ }$ & $\sqrt{ }$ & $\sqrt{ }$ & $\sqrt{ }$ & $\sqrt{ }$ & $\sqrt{ }$ \\
\hline Tool quick return time & & & $\sqrt{ }$ & & & & & & & \\
\hline \multicolumn{11}{|l|}{ Carbon Emission } \\
\hline $\begin{array}{l}\text { Electricity energy } \\
\text { consumption }\end{array}$ & & & & & $\sqrt{ }$ & $\sqrt{ }$ & $\sqrt{ }$ & $\sqrt{ }$ & $\sqrt{ }$ & $\sqrt{ }$ \\
\hline Cutting tool production & $\sqrt{ }$ & & & & $\sqrt{ }$ & $\sqrt{ }$ & $\sqrt{ }$ & & & $\sqrt{ }$ \\
\hline $\begin{array}{l}\text { Cutting fluid } \\
\text { production }\end{array}$ & & & & & $\sqrt{ }$ & $\sqrt{ }$ & $\sqrt{ }$ & & & $\sqrt{ }$ \\
\hline $\begin{array}{l}\text { Raw material } \\
\text { production }\end{array}$ & $\sqrt{ }$ & & & & $\sqrt{ }$ & & & & & $\sqrt{ }$ \\
\hline Material waste removal & $\sqrt{ }$ & & & & $\sqrt{ }$ & & & $\sqrt{ }$ & $\sqrt{ }$ & $\sqrt{ }$ \\
\hline Tool changing & $\sqrt{ }$ & & & & & & & & & \\
\hline Idle machine & $\sqrt{ }$ & & & & & & & & & \\
\hline
\end{tabular}

Table 1. Summary of related research 
In this research, we extend the research of Widhiarso and Rosyidi (2018) with two extensions. First, we involve the carbon emission as one of the objective functions replacing for the environmental impact objective function. In their research, the environmental impact was measured using Eco Indicator 99 which not specifically measure carbon emission in detail. In this research we calculate a more detailed carbon emissions from electrical energy, the production of cutting tool, cutting fluid, and raw material, as well as chip removal. Second, we add a real machining to validate the optimization results.

\section{Research Methodology \\ 2.1. Multi Objective Optimization}

In this research, we employ multi objective optimization to model the machining process of a certain work piece. The multi objective optimizations are found in many fields of research. Emmerich and Deutz (2018) explained the basic mathematical foundation of multi objective optimization and the fundamentals and applications of several evolutionary algorithm in such optimization. According to Al-Jamimi, BinMakhashen, Deb and Saleh (2021), multi objective optimization allows for finding the optimal solutions directly and simultaneously to achieve the desired objectives by satisfying a set of constraints. Further, Audet, Bigeon and Cartier (2020) found 63 performance indicators in their review on multi objective optimization papers. Those indicators are then culstered into four groups according to their properties, cardinality, convergence, distribution and spread. They also presented the application of those indicators.

In literature, a multi objective optimization problem may be solved using several methods and the most robust method is by using transformation function (Marler \& Arora, 2004). The transformation is commonly used to aggregate the different units in the objective functions to become dimensionless. In this research, the objective functions has two of different units which should be transformed as can be expressed in Equation (33) (Koski, 1984; Koski \& Silvennoinen, 1987; Rao \& Freiheit, 1991).

$$
F_{i}^{\text {trans }}=\frac{F_{i}(x)-F_{i}^{0}}{F_{i}^{\max }-F_{i}^{o}}
$$

In Equation (33), $F_{i}^{\text {trans }}$ is the transformed objective function which has the value between zero and one, $F_{i}(x)$ is the original objective function, $F_{i}^{o}$ and $F_{i}^{m a x}$ are the minimum and maximum value of the objective function respectively.

Each objective function in multi objective optimization has different weight. The most common approach to multi objective optimization is the weighted sum method (Marler \& Arora, 2010). The weighted sum (U) is the product of the objective function and weight of each objective function based on the value given by the decision maker $\left(w_{i}\right)$. The weights are determined based on the decision maker preference which shows the relative importance among the objective functions. The weighted sum with two objective functions can be expressed in Equation (34) as follow:

$$
U=w_{1} \cdot F_{1}(x)+w_{2} \cdot F_{2}(x)
$$

\subsection{Real Machining Application}

In this research, after the optimal solution was found, a real machining application is performed. The real machining application is used to show the applicability of the proposed model and validate the results of optimization. The cutting speed dan feed rate as the solution of the optimization model will be implemented in a real machining using Gedee Weiler Leanturn CNC lathe machine with workpiece material made from cylindrical Mild Steel (ST 370) as shown in Figure 1 and Figure 2 respectively. The diameter of the workpiece $(D)$ is $20 \mathrm{~mm}$ and the turning length $\left(L_{j}\right)$ is $15.7 \mathrm{~mm}(0.25 \pi \mathrm{D})$. The surface roughness $\left(R_{\max }\right)$ is required to be less than $6.4 \mu \mathrm{m}$ with the cutting depth $\left(a_{j p}\right)$ of $0.3 \mathrm{~mm}$ and the maximum cutting force $\left(F_{\text {max }}\right)$ of $9000 \mathrm{~N}$. The specification of the machine is shown in Table 2. 


\begin{tabular}{|c|c|}
\hline Parameters & Specifications \\
\hline Spindle motor power, $P(\mathrm{~kW})$ & 3.7 \\
\hline Spindle speed, $n_{\min }-n_{\max }(\mathrm{rev} / \mathrm{min})$ & $50-5000$ \\
\hline Feed velocity maximum, $v f_{\max }(\mathrm{mm} / \mathrm{min})$ & 6000 \\
\hline Rapid moving speed $(\mathrm{m} / \mathrm{min})$ & $\begin{array}{c}\mathrm{X}_{\text {axis }}=20 \\
\mathrm{Z}_{\text {axis }}=25\end{array}$ \\
\hline Machine Efficiency, $\eta$ & 0.8 \\
\hline
\end{tabular}

Table 2. Specification of Leanturn CNC Lathe

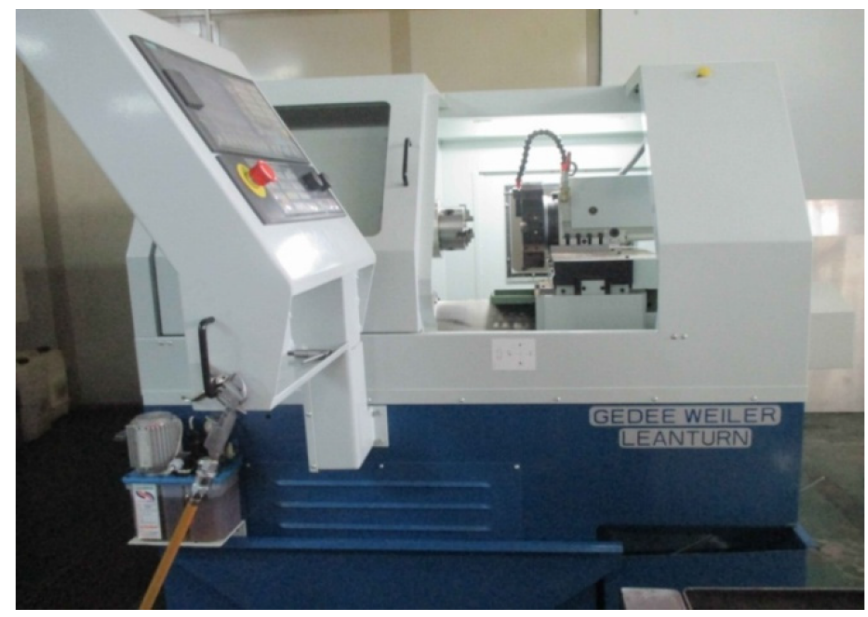

Figure 1. Leanturn CNC lathe

The cutting fluid or coolants are required during the machining process to cooling the heat resulting from the cutting tool and workpiece, and minimizing chip on cutting tool edges. The type of cutting fluid or coolants used during the machining process is Emulkat 500 mixed with water. The machine will process a radius cutting and done feeding one time as depicted in Figure 2.

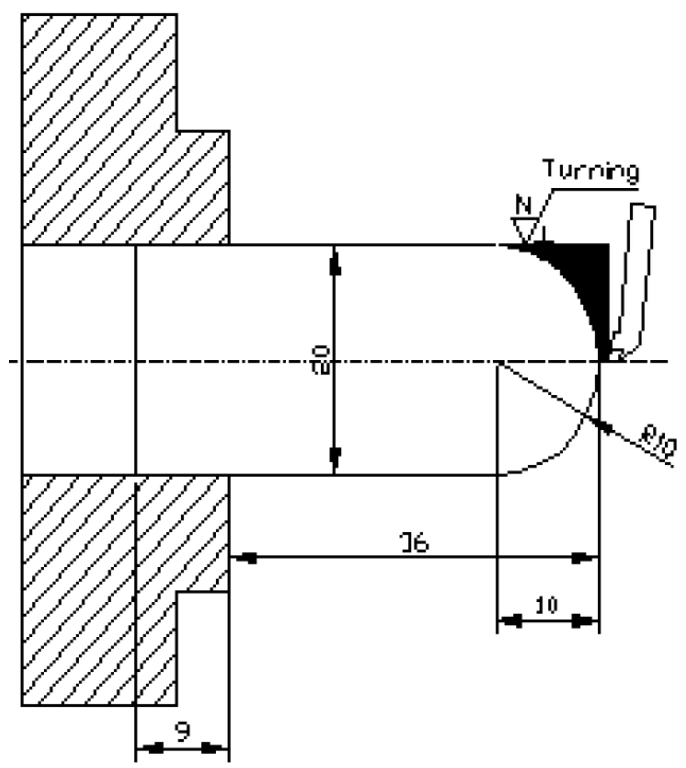

Figure 2. The workpiece 


\section{Model Development}

In this section we present the model development both objective functions and constraints. Hence, the optimization model has two objectives and will be solved using multi objective optimization method.

\subsection{Processing Time}

The processing time $\left(T_{p}\right)$ used in this paper refers to Liu et al. (2016) in which expressed as the sum of auxiliary time $\left(t_{o t}\right)$ and cutting time $\left(t_{m}\right)$.

$$
T_{p}=t_{o t}+t_{m}
$$

The auxiliary time $\left(t_{o t}\right)$ in the machining process consists of starting time, tool setting time, tool changing time, and idle running time which can be expressed as in Equation (2).

$$
t_{o t}=t_{1}+t_{2}+\frac{t_{3} \cdot t_{m}}{T_{t}}+t_{4}
$$

The tool life $\left(T_{t}\right)$ is determined based on Taylor's equation formula and can be expressed in Equation (3) (Kalpakjian \& Schmid, 2003).

$$
T_{t}=\frac{C T}{v_{c}^{x} \cdot f^{y} \cdot a_{j p}{ }^{z}}
$$

In Equation (3), $C T$ is coefficient of machining parameters, $x, y, z$ are exponent of cutting speed, feed rate, and cutting depth.

The idle running time $\left(t_{4}\right)$ is the temporary idle operation during the turning process and can be expressed in Equation (4). In the processing time, the feed time of cutting tool in the idle operation considered as the auxiliary time (Liu et al., 2016).

$$
t_{4}=\sum_{j=1}^{N}\left(\frac{2 L_{x}}{v_{x}}+\frac{L_{j}+L_{z}}{v_{z}}\right)
$$

The cutting time related with the length of turning process and machining parameter (Yi et al., 2015) and obtained from the sum of every turning process. The turning process time $\left(t_{j m}\right)$ to process a radius can be expressed in Equation (5) and the cutting time $\left(t_{m}\right)$ is shown in Equation (6).

$$
\begin{gathered}
t_{j m}=\frac{\frac{1}{2} \cdot\left(\pi\left(\frac{D}{2}\right)^{2}\right) \cdot a_{j p}}{v_{c} \cdot f}=\frac{\frac{1}{8} \cdot \pi \cdot D^{2} \cdot a_{j p}}{v_{c} \cdot f} \\
t_{m}=\sum_{j=1}^{N} t_{j m}
\end{gathered}
$$

Therefore, the proposed model of processing time $\left(T_{p}\right)$ can be expressed as follows:

$$
T_{p}=t_{1}+t_{2}+\frac{t_{3} \cdot \sum_{j=1}^{N} \frac{\frac{1}{8} \pi D^{2} a_{j p}}{v_{c} f}}{\frac{C_{T}}{v_{c}^{x} \cdot f^{y} \cdot a_{j p}^{z}}}+\sum_{j=1}^{N}\left(\frac{2 L_{x}}{v_{x}}+\frac{L_{j}+L_{z}}{v_{z}}\right)+\sum_{j=1}^{N} \frac{\frac{1}{8} \pi D^{2} a_{j p}}{v_{c} f}
$$




\subsection{Carbon Emissions}

The carbon emissions of a CNC machining process are generated from the emissions of electricity, the production of cutting tool, cutting fluid, and raw material, and the chip removal (Li et al., 2013). In this research, the carbon emissions refers to Liu et al. (2016) for emissions from the electricity energy, cutting tool, and cutting fluid or coolant, while raw material production and chip removal refers to Li et al. (2013). The proposed carbon emissions (CE) model can be calculated by Equation (8) as follows:

$$
C E=C E_{e}+C E_{t}+C E_{c}+C E_{m}+C E_{c h i p}
$$

\subsubsection{Carbon Emissions of Electricity Energy}

The carbon emissions from the electricity energy $\left(C E_{e}\right)$ can be calculated by Equation (9) (Jeswiet \& Kara, 2008).

$$
C E_{e}=F_{e} \cdot E
$$

The total electricity energy $(E)$ in machining process consists of the energy consumption in the auxiliary machining and cutting process which can be expressed in Equation (10).

$$
E=E_{1}+E_{2}
$$

The energy consumption of the auxiliary machining $\left(E_{1}\right)$ can be calculated by Equation (11) (Liu et al., 2016). The energy consumption of machine starting process $\left(E_{00}\right)$ can be shown in Equation (12), while the idle power of machine $\left(P_{01}\right)$ related to spindle speed and its specification as expressed in Equation (13) (Liu, Hu, He \& Hu, 2012).

$$
\begin{gathered}
E_{1}=\frac{1}{N_{p}} \int_{0}^{t_{1}} P(t) d t+\left(P_{01}+P_{s}\right)\left(t_{2}+\frac{t_{3} \cdot t_{m}}{T_{t}}+t_{4}\right) \\
E_{00}=\frac{1}{N_{p}} \int_{0}^{t_{1}} P(t) d t \\
P_{01}=P_{0}+A_{1} n+A_{2} n^{2}
\end{gathered}
$$

The energy consumption in the cutting process $\left(E_{2}\right)$ can be calculated using Equation (14) (Liu et al., 2016). Xu, Wang, Teng, Zhong and Teng (2015) explained that the power of machine can produce the actual cutting power $(P c)$ and the additional load power $\left(P_{a}\right)$ during machining process. The additional load power $\left(P_{a}\right)$ can be expressed in Equation (15). The actual cutting power $\left(P_{c}\right)$ is expressed as the function of cutting force $\left(F_{c}\right)$ and cutting speed $\left(v_{c}\right)$ as shown in Equation (16), while the cutting force $\left(F_{c}\right)$ can be calculated using Equation (17).

$$
\begin{gathered}
E_{2}=\sum_{j=1}^{N}\left(\frac{1+b_{m}}{1000} C_{F C} a_{j p}^{x_{F C}} f^{y_{F C}} v_{c}^{n_{F C}+1} K_{F C} \cdot t_{j m}\right) \\
+\left(P_{s}+P_{01}\right) t_{m} \\
P_{a}=b_{m} \cdot P_{c} \\
P_{c}=F_{c} \cdot v_{c} \\
F_{c}=C_{F C} a_{j p}^{x_{F C}} f^{y_{F C}} v_{c}^{n_{F C}} K_{F C}
\end{gathered}
$$


In Equation (14) and (17), $x_{F C}, y_{F C}, n_{F C}$ are coefficients of depth of cut, feed rate, and cutting speed, $C_{F C}$ is cutting force coefficient of workpiece material, $K_{F C}$ is factor influence coefficient of cutting force.

\subsubsection{Carbon Emissions of Cutting Tool Production}

The carbon emissions generated from the cutting tool production $\left(C E_{t}\right)$ comes from tool material extraction and tool manufacturing which can be calculated in Equation (18) (Liu et al., 2016):

$$
C E_{t}=\frac{t_{m}}{T_{t}}\left(F_{t 1} \cdot w_{t}+F_{t 2} \cdot E_{t}\right)
$$

\subsubsection{Carbon Emissions of Cutting Fluid Production}

The carbon emissions generated from the cutting fluid production $\left(C E_{c}\right)$ consists of the production process, waste fluid removal, and electricity energy consumed to supply pump. The cutting fluid supply time assumed as the total processing time comprises of the auxiliary time and cutting time (Liu et al., 2016):

$$
C E_{C}=\frac{1}{N_{Q}} T_{t o t a l} B_{c}\left(\delta F_{q 1}+F_{q 2}\right)+F_{e} P_{p} T_{\text {total }}
$$

\subsubsection{Carbon Emissions of Raw Material Production}

The $\mathrm{CNC}$ machine is an automatic machine to process material to become semi-finished or finished products. The carbon emissions of raw material production $\left(C E_{m}\right)$ removed is calculated by Equation (20) (Li et al., 2013).

$$
C E_{m}=C E F_{m} \cdot M_{c h i p}
$$

The embodied material energy is then converted into the standard coal with the content of coal carbon which can be determined as in Equation (21) (Li et al., 2013):

$$
C E F_{m}=C E F_{c e} \cdot E E_{c e}
$$

The removed material $\left(M_{c h i p}\right)$ is measured by calculating the difference between mass of the raw material and semifinished or finished products which can be expressed in Equations (22) and (23) respectively (Li et al., 2013). In Equation (22) and (23), Q is removal rate.

$$
\begin{gathered}
M_{c h i p}=\frac{Q \cdot t_{m} \cdot \rho}{10^{6}}=\frac{v_{c} \cdot f \cdot a_{j p} \cdot t_{m} \cdot \rho}{1000} \\
Q=1000 v_{c} \cdot f \cdot a_{j p}
\end{gathered}
$$

\subsubsection{Carbon Emissions of Chip Removal}

The chip recycle is often used to recover the raw material. The carbon emissions generated from the electricity to recycling process can be expressed in Equations (24) and (25) respectively (Li et al., 2013).

$$
\begin{aligned}
& C E_{\text {chip }}=C E F_{\text {chip }} \cdot M_{c h i p} \\
& C E F_{c h i p}=C E F_{c e} \cdot E C_{c e}
\end{aligned}
$$

The proposed carbon emissions $(C E)$ model can be expressed as follows: 


$$
\begin{aligned}
& C E=F_{e}\left(\begin{array}{l}
\frac{1}{N_{p}} \cdot \int_{0}^{t_{1}} P(t) d t+\left(P_{0}+A_{1} \frac{1000 v_{c}}{\pi D}+A_{2}\left(\frac{1000 v_{c}}{\pi D}\right)^{2}+P_{s}\right)\left(t_{2}+\frac{t_{3} \cdot t_{m}}{T_{t}}+t_{4}\right) \\
+\sum_{j=1}^{N}\left(\frac{\left(1+b_{m}\right)}{1000} C_{F C} a_{j p}^{x_{F C}} f^{y_{F C}} v_{c}^{n_{F C}+1} K_{F C} t_{j m}\right)+\left(P_{s}+P_{01}\right) \cdot t_{m}
\end{array}\right) \\
& +\frac{t_{m}}{T_{t}} \cdot\left(F_{t 1} \cdot w_{t}+F_{t 2} \cdot E_{t}\right)+\frac{1}{N_{Q}} \cdot\left(t_{o t}+t_{m}\right) \cdot B_{c} \cdot\left(\delta \cdot F_{q 1}+F_{q 2}\right)+F_{e} \cdot P_{p} \cdot\left(t_{o t}+t_{m}\right) \\
& +\left(C E F_{c e} \cdot E E_{c e}\right)\left(\frac{v_{c} f a_{j p} t_{m} \rho}{1000}\right)+\left(C E F_{c e} \cdot E C_{c e}\right)\left(\frac{v_{c} f a_{j p} t_{m} \rho}{1000}\right)
\end{aligned}
$$

In this research, several constraints are considered, namely power, cutting force, and surface roughness. The complete model can be stated as follow:

Minimize

$$
F(v c, f)=\{T p(v c, f), C E(v c, f)\}
$$

Subject to

$$
\begin{gathered}
\frac{\pi D n_{\min }}{1000} \leq v_{c} \leq \frac{\pi D n_{\max }}{1000} \\
f_{\min } \leq f \leq f_{\max } \\
C_{F C} a_{j p}^{x_{F C}} f^{y_{F C}} v_{c}^{n_{F C}} K_{F C} \leq F_{\max } \\
\frac{\left(1+b_{m}\right) C_{F C} a_{j p}^{x_{F C}} f^{y_{F C}} v_{c}^{n_{F C}+1} K_{F C}}{1000 \eta} \leq P_{\max } \\
R_{a}=\frac{1000 f^{2}}{32 r_{\varepsilon}} \leq R_{\max }
\end{gathered}
$$

The constraint in Equation (28) defines the solution space of the model to control the cutting speed within the value limit of minimum and maximum $\left(n_{\min }\right.$ and $\left.n_{\max }\right)$ according to the minimum and maximum spindle speed of the machine. The constraint in Equation (29) controls the feed rate based on the combination of workpiece material and cutting tool which must be in the value limit of minimum and maximum $\left(f_{\text {min }}\right.$ and $\left.f_{\text {max }}\right)$. Equation (30) to prevents the breakage in cutting edges where the cutting force must not exceed the allowable maximum cutting force of the machine. Equation (31) is needed to ensure the power of cutting must not exceed the allowable maximum power of the machine. Lastly, Equation (32) ensures the surface roughness as the control of quality requirement.

\section{Results and Discussion}

\subsection{Optimization Results}

The cutting tool used during the machining process is tungsten carbide insert tool with the specifications given in Table 3. Considering the workpiece materials and cutting tool used during the machining process, then the coefficient of cutting tool hardiness can be shown in Table 4 (Yi et al., 2015) and the coefficient of cutting force are shown in Table 5. In this research, the coefficients of cutting force $\left(C_{F C}\right)$ are obtained from the Technical Data Formula for Cutting Power. 


\begin{tabular}{|l|c|}
\hline \multicolumn{2}{|c|}{ Model Parameters } \\
\hline Type of cutting tool & Tungsten Carbide \\
\hline Corner radius, $r$ & 0.8 \\
\hline Feed rate, $f(\mathrm{~mm} / \mathrm{rev})$ & $0.1-0.5$ \\
\hline Weight of cutting tool, $W_{t}(\mathrm{gr})$ & 15 \\
\hline
\end{tabular}

Table 3. Specification of Cutting Tool

\begin{tabular}{|c|r|r|r|}
\hline$C_{T}$ & \multicolumn{1}{|c|}{$\boldsymbol{x}$} & \multicolumn{1}{c|}{$\boldsymbol{y}$} & \multicolumn{1}{c|}{$\boldsymbol{z}$} \\
\hline $6.4136 \times 10^{9}$ & 5 & 1.75 & 0.75 \\
\hline
\end{tabular}

Table 4. Coefficient of Cutting Tool Hardness

\begin{tabular}{|l|c|r|r|r|c|}
\hline \multirow{2}{*}{ Workpiece Material } & \multicolumn{5}{|c|}{ Coefficient Cutting Force } \\
\cline { 2 - 6 } & \multicolumn{1}{|c|}{$\boldsymbol{C}_{F C}$} & \multicolumn{1}{|c|}{$\boldsymbol{K}_{F C}$} & \multicolumn{1}{c|}{$\boldsymbol{x}_{F C}$} & \multicolumn{1}{c|}{$\boldsymbol{y}_{F C}$} & $\boldsymbol{n}_{F C}$ \\
\hline Mild steel (ST 370) & 3100 & 1 & 1.0 & 0.75 & -0.15 \\
\hline
\end{tabular}

Table 5. Coefficient of Cutting Force

\begin{tabular}{|l|r|}
\hline \multicolumn{1}{|c|}{ Parameters } & Specifications \\
\hline Load loss power coefficient, $b_{m}$ & 0.2 \\
\hline Carbon emission factors of electricity, $F_{e}\left(\mathrm{kgCO}_{2} / \mathrm{kWh}\right)$ & 0.6747 \\
\hline Energy consumption in the tool manufacturing, $E_{t}(\mathrm{MJ})$ & 1.5 \\
\hline Carbon emission factors of cutting tool, $F_{t}(\mathrm{kgCO} / \mathrm{kWh})$ & 0.6747 \\
\hline Concentration of cutting fluid, $\delta(\%)$ & 5 \\
\hline Flow of cutting fluid, $B_{c}(\mathrm{~L} / \mathrm{min})$ & 19 \\
\hline Supply pump power of cutting fluid, $P_{p}(\mathrm{~W})$ & 40 \\
\hline Carbon emission factors of production process, $F_{q 1}\left(\mathrm{kgCO}_{2} / \mathrm{L}\right)$ & 2.85 \\
\hline Carbon emission factors of waste cutting fluid, $F_{q^{2}}\left(\mathrm{kgCO}_{2} / \mathrm{L}\right)$ & 0.2 \\
\hline Amount of recycled cutting fluid, $N_{Q}$ & 520 \\
\hline
\end{tabular}

Table 6. Parameters of Carbon Emissions

The number of workpieces to be processed for each machining $\left(N_{p}\right)$ are 520 parts, the starting time $\left(t_{1}\right)$ is $10.2 \mathrm{~s}$, the tool setting time $\left(t_{2}\right)$ is $180 \mathrm{~s}$, and the tool changing time $\left(t_{3}\right)$ is $20 \mathrm{~s}$. The energy consumption in the machine start process $\left(E_{00}\right)$ is $0.12 \mathrm{~W}$. Based on Table 2, the power consumption of auxiliary tool $\left(P_{s}\right)$ is $3700 \mathrm{~W}$, the rapid moving speed in $\mathrm{X}$ axis $\left(v_{x}\right)$ is $0.333 \mathrm{~m} / \mathrm{s}$ and the rapid moving speed in $\mathrm{Z}$ axis $\left(v_{v}\right)$ is $0.417 \mathrm{~m} / \mathrm{s}$. From reference of the cutting tool during machining process, the distance return to the first position of $\mathrm{X}$ axis $\left(L_{x}\right)$ is $20 \mathrm{~mm}$ and the distance return to the first position of $\mathrm{Z}$ axis $\left(L_{2}\right)$ is $50 \mathrm{~mm}$. The minimum idle power of machine $\left(P_{0}\right)$ is $40 \mathrm{~W}$, the coefficient of spindle speed $\left(A_{1}\right.$ and $\left.A_{2}\right)$ are 0.227 and $-0.667 \times 10^{-6}$ respectively (Liu et al., 2016). The parameters of carbon emissions to calculate the carbon emissions from electricity, cutting tool, and cutting fluid are shown in Table 6.

The carbon emission factors of material $\left(C E F_{m}\right)$ and the carbon emission factors of chip $\left(C E F_{\text {chip }}\right)$ are converted to the standard coal (Li et al., 2013). The workpiece material used is Mild Steel (ST 370), then the carbon emission factors of coal $\left(C E F_{\alpha}\right)$ is $2.47 \mathrm{kgCO}_{2} / \mathrm{kg}$ ce, the standard coal of embodied material energy $\left(E E_{c}\right)$ is $1.09 \mathrm{~kg} \mathrm{ce} / \mathrm{kg}$, and the standard coal consumption in the recycling process $\left(E C_{a}\right)$ is $0.146 \mathrm{~kg} \mathrm{ce} / \mathrm{kg}$. The material density $(\rho)$ is $7.8 \mathrm{~g} / \mathrm{cm}^{3}$ (Walsh \& Cormier, 2006). 
The proposed optimization model is solved using Oracle Crystal Ball software with 10,000 iterations to obtain the optimal solution. This software has been used in many researches to solve various optimization models, such as in Rosyidi, Murtisari and Jauhari (2016), Rosyidi, Fatmawati and Jauhari (2016) and Guerra, Bozo, Vyhmeister, Salazar, Caparros and Clemente-Jul (2020). It is a powerful Excel based software to solve both deterministic and stochastic model, including the Monte Carlo simulation. For optimization problems, the software has OptQuest function to help find the best global solutions using multiple, complimentary search methodologies, including advanced tabu search and scatter search. The results of the optimization solved individually for each the objective function are shown in Table 7 while the results of optimization using multi objective model are shown in Table 8 . Table 8 shows that the optimal cutting speed and feed rate are $193.7 \mathrm{~m} /$ minute and $0.405 \mathrm{~mm} / \mathrm{rev}$ respectively with the objective function of 0.082 . The results indicate that the optimal cutting speed is within the value limit of minimum and maximum of cutting speed in the processing time and carbon emissions.

\begin{tabular}{|l|r|r|}
\hline \multicolumn{1}{|c|}{ Objective Function } & \multicolumn{1}{c|}{ Minimize } & \multicolumn{1}{c|}{ Maximize } \\
\hline Processing time, $T_{p}(\mathrm{~s})$ & $32,226.92$ & $490,116.71$ \\
\hline Carbon emission, $\mathrm{CE}\left(\mathrm{kgCO}_{2}\right)$ & $165,023.06$ & $328,614.98$ \\
\hline
\end{tabular}

Table 7. Result of Optimization for Each Objective Function

\begin{tabular}{|l|r|}
\hline Objective function & 0.082 \\
\hline Cutting speed, $v_{c}(\mathrm{~m} /$ minute $)$ & 193.7 \\
\hline Feed rate, $f(\mathrm{~mm} / \mathrm{rev})$ & 0.405 \\
\hline
\end{tabular}

Table 8. Multi Objective Optimization

\subsection{Real Machining Application}

Based on the results of optimization, a validation is made using real machining application. We use the optimal cutting speed and feed rate in the machining process of 30 units of the workpiece. Afterwards, a surface roughness measurement will be done on 3 points at the surface of each workpiece. The surface roughness will be compared with the results of machining of the same workpiece using the optimal cutting speed with recommended feed rate from machining expert at $0.2 \mathrm{~mm} / \mathrm{rev}$. Mitutoyo Surface Roughness Tester SJ-201P was used to measure the roughness. The basic descriptive statistics of the data are shown in Table 9. From the table we can observe that the mean of surface roughness based on optimal results of optimization has much higher roughness than the one based on recommendation. This results are commonly knowledgable that higher feed rate will results higher surface roughness. It also conforms the common function used to estimate the surface roughness where the function is assumed to have linear relationship between surface roughness and the feed rate as shown in Equation 32. However, the surface roughness mean based on optimization results are still satisfy the surface roughness constraint of the model of $6.4 \mu \mathrm{m}$

\begin{tabular}{|l|r|r|r|r|}
\hline \multicolumn{1}{|c|}{ Surface Roughness } & \multicolumn{1}{c|}{ Mean } & Variance & Minimum & Maximum \\
\hline Expert Recommendation & 1.36 & 0.0049 & 1.27 & 1.49 \\
\hline Optimization Result & 4.33 & 0.018 & 3.87 & 4.47 \\
\hline
\end{tabular}

Table 9. Descriptive statistics of the machining application

\subsection{Sensitivity Analysis}

Sensitivity analysis is performed to study how the parameter changes in mathematical model affecting the objective function and decision variables. In this research, we study the change of weight of both objective functions with the results as shown in Table 10. Figures 3 shows graphically the effect of weight on cutting speed, while the effect of weight on the objective function is shown in Figure 4. The weight is insensitive on the feed rate since the change 
weight results in the same value of feed rate. This result may be caused by three parameters that limit the result of optimal feed rate, namely cutting force, machine power, and surface roughness.

\begin{tabular}{|r|r|r|r|r|}
\hline $\begin{array}{l}\text { Weight of Processing } \\
\text { Time }\end{array}$ & $\begin{array}{c}\text { Weight of Carbon } \\
\text { Emission }\end{array}$ & $\begin{array}{c}\text { Objective } \\
\text { Function }\end{array}$ & Cutting Speed & \multicolumn{1}{c|}{ Feed Rate } \\
\hline 0 & 1 & 0 & 314 & 0.405 \\
\hline 0.1 & 0.9 & 0.027 & 292.09 & 0.405 \\
\hline 0.2 & 0.8 & 0.040 & 252.25 & 0.405 \\
\hline 0.3 & 0.7 & 0.044 & 227.07 & 0.405 \\
\hline 0.4 & 0.6 & 0.045 & 208.50 & 0.405 \\
\hline 0.5 & 0.5 & 0.041 & 193.70 & 0.405 \\
\hline 0.6 & 0.4 & 0.036 & 180.93 & 0.405 \\
\hline 0.7 & 0.3 & 0.029 & 169.92 & 0.405 \\
\hline 0.8 & 0.2 & 0.020 & 159.68 & 0.405 \\
\hline 0.9 & 0.1 & 0.011 & 150.63 & 0.405 \\
\hline 1 & 0 & 0 & 141.92 & 0.405 \\
\hline
\end{tabular}

Table 10. Result of Weighted Sum

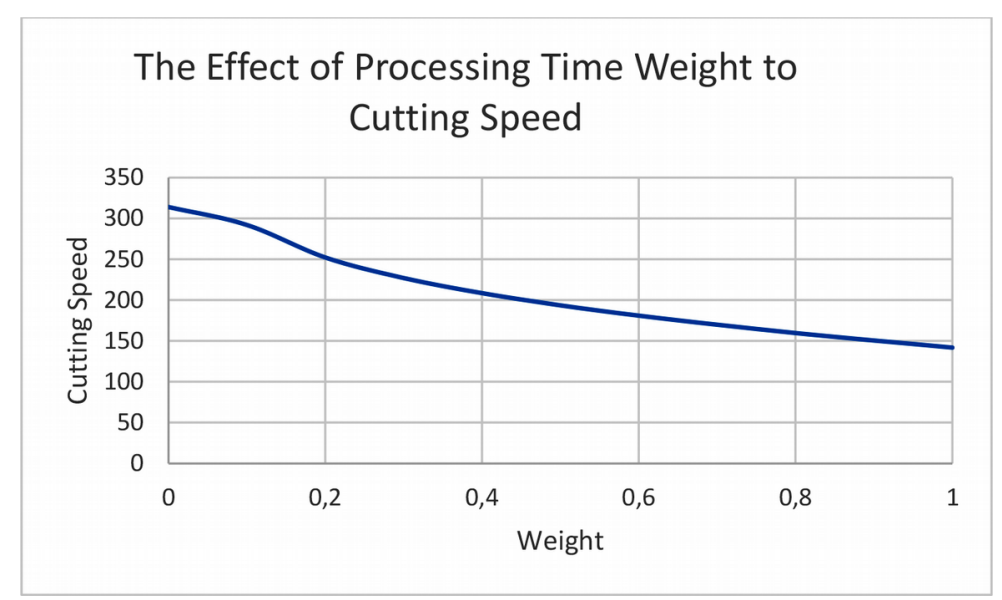

Figure 3. The effect of weight on cutting speed

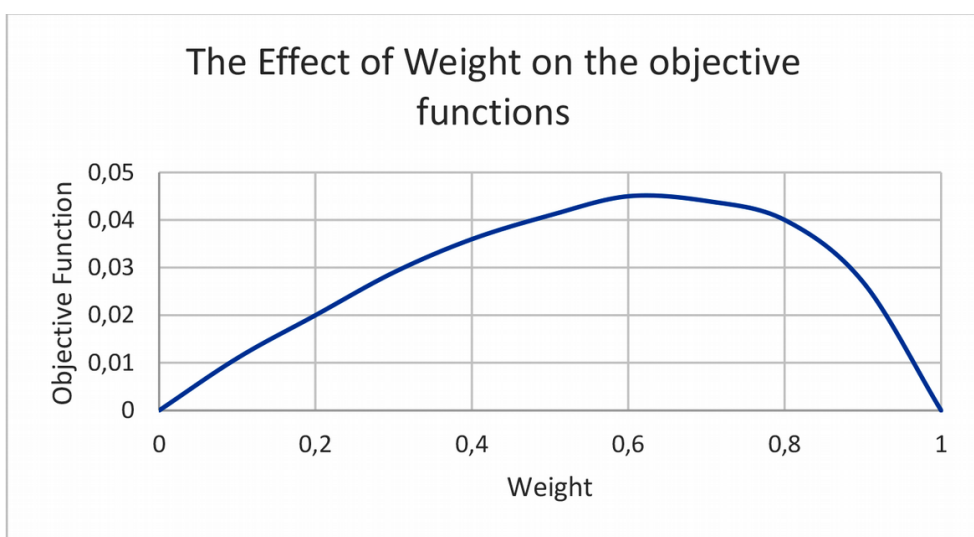

Figure 4. The effect of weight on the objective function 
Further sensitivity analysis should be made to determine which parameters affect the optimal feed rate. Hence, three parameters are added in the sensitivity analysis in the form of upper limit cutting force, machine power, and surface roughness. We change the upper value of those parameters by $50 \%$ lower and $50 \%$ higher than the current value of each parameter. The results of the analysis are shown in Table 11. The table shows that both machining parameters are not sensitive to the upper limits of cutting force and machine power. Surface roughness is the only parameters that sensitive to both machining parameters. The higher the surface roughness, the higher the cutting speed. This result confirmed with many research results in this area. The feed rate move to the opposite direction of cutting speed. The higher the cutting speed, the lower the feed rate and vice versa. The machining parameters tend to balance each other to not exceed the surface roughness. For the highest value of surface roughness in the table, the feed rate achieve its upper limit. Hence, if the surface roughness increase above this value, the feed rate would not change.

\begin{tabular}{|l|r|r|r|r|r|r|r|r|r|}
\hline & \multicolumn{3}{|c|}{ Cutting Force } & \multicolumn{3}{|c|}{ Machine Power } & \multicolumn{3}{c|}{ Surface Roughness } \\
\hline Decision Variables & 5000 & 9000 & 10,615 & 2500 & 3700 & 5500 & 3.2 & 6.4 & 12.5 \\
\hline Cutting Speed & 193.7 & 193.7 & 193.7 & 193.7 & 193.7 & 193.7 & 215.55 & 193.7 & 181.86 \\
\hline Feed Rate & 0.405 & 0.405 & 0.405 & 0.405 & 0.405 & 0.405 & 0.286 & 0.405 & 0.500 \\
\hline
\end{tabular}

Table 11. Results of Sensitivity Analysis on Cutting Force, Machine Power, and Surface Roughness

\section{Conclusions}

Multi objective optimization model was proposed in this research to minimize processing time and carbon emissions to optimize cutting speed and feed rate. The function transformation was used to aggregate the different units of the objective functions. In this research, the optimal cutting speed and feed rate are $193.7 \mathrm{~m} / \mathrm{minute}$ and $0.405 \mathrm{~mm} / \mathrm{rev}$ respectively. The results of sensitivity analysis showed that cutting speed is sensitive to the change of objective function weight. The curve of processing time and carbon emissions were met of both point in the weights of 0.5 which obtained the optimal cutting speed is $193.68 \mathrm{~m} /$ minute. Both machining parameters are not sensitive to the change of cutting force and machine power, but sensitive to the change of surface roughness. For future research can be directed in the use of other raw materials to determine the optimal cutting speed and feed rate for each material which can be used as a guidance by many manufacturing companies to determine those process parameters, can consider the other carbon emissions of tool change or idle machine.

\section{Declaration of Conflicting Interests}

The authors declared no potential conflicts of interest with respect to the research, authorship, and/or publication of this article.

\section{Funding}

This research was supported by Lembaga Penelitian dan Pengabdian Masyarakat Universitas SebelasMaret under Mandatory Research Grant with Contract Number 452/UN27.21/PN/2020.

\section{References}

Al-Jamimi, H.A., BinMakhashen, G.M., Deb, K., \& Saleh, T.A. (2021). Multiobjective Optimizationand Analysis of Petroleum Refinery Catalytic Processes: A Review. Fuel, 288. https://doi.org/10.1016/j.fuel.2020.119678

Audet, C., Bigeon, J., \& Cartier D. (2020). Performance indicators in multiobjective optimization. European Journal of Operational Research. Accepted manuscript.

Berk, J. (2010). Cost Reduction and Optimization for Manufacturing and Industrial Companies. New York: Wiley and Scrivener. https://doi.org/10.1002/9780470643815

Deepak, S.S.K. (2012). Cutting Speed and Feed Rate Optimization for Minimizing Production Time of Turning Process. International Journal of Modern Engineering Research (IJMER), 2, 3398-3401. 
Emmerich, M.T.M., \& Deutz, A.H. (2018). A Tutorial on Multiobjective Optimization: Fundamentals and Evolutionary Methods. Natural Computing, 17, 585-609. https://doi.org/10.1007/s11047-018-9685-y

Guerra, C.F., Bozo, L.R., Vyhmeister, E., Salazar, J.L., Caparros, J. M., \& Clemente-Jul, C. (2020). Sustainability of Hydrogen Refuelling Stations for Trains Using Electrolysers. International Journal of Hydrogen Energy. In Press. https://doi.org/10.1016/j.ijhydene.2020.10.044

Hamada, A., Rosyidi, C.N., \& Jauhari, W.A. (2017). Multi-Objective Optimization Model of CNC Machining to Minimize Processing Time and Environmental Impact. 3rd International Materials, Industrial and Manufacturing Engineering Conference (MIMEC2017), AIP Conference Proceedings, 1902, 1-7. https://doi.org/10.1063/1.5010653

Hassine, H., Barkallah, M., Bellacicco, A., Louati, J., Riviere, A., \& Haddar, M. (2015). Multi Objective Optimization for Sustainable Manufacturing Application in Turning. International Journal Simulation Model, 14(1), 98-109. https://doi.org/10.2507/IJSIMM14(1)9.292

Jabri, A., Barkany, A.E., \& Khalfi, A.E. (2013). Multi-Objective Optimization Using Genetic Algorithm of MultiPass Turning Process. Journal Engineering, 5, 601-610. https://doi.org/10.4236/eng.2013.57072

Jeswiet, J., \& Kara, S. (2008). Carbon Emission and CES in Manufacturing. CIRP Annualing Manufacturing Tecnologies, 57, 17-20. https://doi.org/10.1016/j.cirp.2008.03.117

Kalpakjian, S., \& Schmid, S.R. (2003). Manufacturing Processes for Engineering Material. New Jersey: Prentice Hall.

Koski, J. (1984). Multicriterion Optimization in Structural Design. In Artrek, E., Gallagher, R.H., Ragsdell, K.M., \& Zienkiewicz, O.C. (Eds.), New Directions in Optimum Structural Design (483-503). New York: John Wiley and Sons.

Koski, J., \& Silvennoinen, R. (1987). Normalization Methods and Partial Weighting in Multicriterion Optimization of Structures. International Journal Numerical Methods Engineering, 24, 1101-1121.

https://doi.org/10.1002/nme.1620240606

Li, C., Tang, Y., Cui, L., \& Yi, Q. (2013). Quantitative Analysis of Carbon Emissions of CNC-based Machining Systems. Proceedings of IEEE 10th International Conference on Networking, Sensing and Control (869-874).

Liu, F., Hu, S.H., He, Y., \& Hu, T. (2012). No-load Energy Parameter Characteristic of Computerized Numerical Control Machine Tool Main Transmation System. Computing Integration Manufacturing Systems, 18(2), 326-331.

Liu, Z.J., Sun, D.P., Lin, C.X., Zhao, X.Q., \& Yang, Y. (2016). Multi-Objective Optimization of the Operating Conditions in a Cutting Process Based on Low Carbon Emission Costs. Journal of Cleaner Production, 124, $266-275$. https://doi.org/10.1016/j.jclepro.2016.02.087

Marler, R.T., \& Arora, J.S. (2004). Survey of Multi-Objective Optimization Methods for Engineering. Structural and Multidisciplinary Optimization, 26, 369-395. https://doi.org/10.1007/s00158-003-0368-6

Marler, R.T., \& Arora, J.S. (2010). The Weighted Sum Method for Multi-Objective Optimization: New Insights. Structural and Multidisciplinary Optimization, 41, 853-862. https://doi.org/10.1007/s00158-009-0460-7

Rajemi, M.F., Mativenga, P.T., \& Aramcharoen, A. (2010). Sustainable Machining: Selection of Optimum Turning Conditions Based on Minimum Energy Considerations. Journal of Cleaner Production, 18, 1059-1065. https://doi.org/10.1016/j.jclepro.2010.01.025

Rao, S.S., \& Freiheit, T.I. (1991). A Modified Game Theory Approach to Multiobjective Optimization. Journal Mechanical Decisions, 113, 286-291. https://doi.org/10.1115/1.2912781

Rochim, T. (2007). Process Classification, Force, and Power Machining. Bandung: ITB (in Bahasa).

Rosyidi, C.N., Murtisari, R., \& Jauhari, W.A (2016). A Concurrent Optimization Model for Suppliers Selection, Tolerance and Component Allocation with Fuzzy Quality Loss. Cogent Engineering, 3(1), 1-10. https://doi.org/10.1080/23311916.2016.1222043 
Rosyidi, C.N., Fatmawati, A., \& Jauhari, W.A. (2016). An Integrated Optimization Model for Product Design and Production Allocation in A Make to Order Manufacturing System. International Journal of Technology, 7(5), 819-830. https://doi.org/10.14716/ijtech.v7i5.1173

Sai, N.K., Charyulu, T.N., \& Nayak, M.S. (2012). Multi Objective Optimization of Machining Parameters by Using Weighted Sum Genetic Algorithm Approaches. International Journal of Engineering Research \& Technology (IJERT), 1, $1-7$.

Subagio, D.G. (2012). Application and CNC Programming in Industrial World. Bandung: Informatika (in Bahasa).

Sun, Q., \& Zhang, W. (2012). Carbon Footprint Analysis in Metal Cutting Process. Proceedings of International Conference on Mechanical Engineering and Material Science (MEMS 2012) (619-622).

Technical Data Formula for Cutting Power. Specific Cutting Force, G015. Available at: http://www.teraskonttori.fi/easydata/customers/teraskonttori/files/lastuavat/Mitsu 14 TECHNICAL DATA.pdf (Accessed: March 2018.)

Walsh, R.A., \& Cormier, D.R. (2006). McGraw-Hill Machining and Metalworking Handbook (3rd ed.). McGraw-Hill Companies, Inc.

Widhiarso, W, \& Rosyidi, C.N. (2018). Multi Objective Optimization Model for Minimizing Production Cost and Environmental Impact in CNC Turning Process. 3th International Conference on Industrial, Mechanical, Electrical, and Chemical Engineering, AIP Conference Proceedings (1931, 1-7). https://doi.org/10.1063/1.5024083

Xu, Z.Z., Wang, Y.S., Teng, Z.R., Zhong, C.Q., \& Teng, H.F. (2015). Low-carbon Product Multi-objective Optimization Design for Meeting Requirements of Enterprise, User, and Government. Journal Cleaner Production, 103, 747-758. https://doi.org/10.1016/j.jclepro.2014.07.067

Yi, Q., Li, C., Tang, Y., \& Chen, X. (2015). Multi-Objective Parameter Optimization of CNC Machining for Low Carbon Manufacturing. Journal of Cleaner Production, 95, 256-264. https://doi.org/10.1016/j.jclepro.2015.02.076

Journal of Industrial Engineering and Management, 2021 (www.jiem.org)

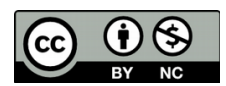

Article's contents are provided on an Attribution-Non Commercial 4.0 Creative commons International License. Readers are allowed to copy, distribute and communicate article's contents, provided the author's and Journal of Industrial Engineering and Management's names are included. It must not be used for commercial purposes. To see the complete license contents, please visit https://creativecommons.org/licenses/by-nc/4.0/. 